\title{
STABILITY INDICATING RELATED SUBSTANCES METHOD FOR BISOPROLOL AND CILNIDIPINE IN BULK AND PHARMACEUTICAL DOSING TYPES AND ITS DEGRADENTS WERE CHARACTERISED BY USE OF LC-MS/MS
}

\author{
Subba Rao Yarlagadda ${ }^{1}$, Subba Rao Mannam*2, K. V. Padmavathi ${ }^{3}$, Y.Pavani ${ }^{4}$. \\ 1, ${ }^{2}$ Department of Chemistry, Acharya Nagarjuna University, Guntur-522510, AP, \\ India. \\ ${ }^{3}$ Department of Chemistry, D. S. Degree College for Women, Ongole, AP, India. \\ ${ }^{4}$ Department of Freshman Engineering, P.V.P Siddhartha Institute of Technology, \\ Kanuru, Vijayawada, AP,India. \\ E.mail ID: mannams145@gmail.com
}

\begin{abstract}
A reliable, simple yetconsistent RP-HPLC method has been developed and verifiedtocombined dosage form of Bisoprolol, Cilnidipine, their relavant substances and characteristic of the degradants by LC-MS/MS. The process used was optimized by using XBridge phenyl column $(150 \mathrm{~mm} \times 4.6 \mathrm{~mm}, 3.5 \mu)$ with a gradient elution mode of mobile phase consists of methanol and $0.1 \%$ tri ethyl amine of $p H-2.5$.The developed RP-HPLC method shows strong linearity in the range of concentrations 2-30 $\mu \mathrm{g} / \mathrm{ml}$ of Bisoprolol, $4-60 \mu \mathrm{g} / \mathrm{ml}$ of Cilnidipine and 0.1-1.5 $\mu \mathrm{g} / \mathrm{ml}$ of Bisoprolol and Cilnidipine impurities. Percentage of regeneration and percentage RSD values were found to be within the allowable limit.The developed method was found to be applicable for routine analysis and utilized for the calculationof both active ingredients and their impurities in tablet dosage form.
\end{abstract}

Key words: Bisoprolol, Cilnidipine, RP-HPLC, Forced degradation, LC-MS/MS

\section{Introduction}

Bisoprolol is used to medicate for cardiovascular disease which involve the heart or blood vessels which may include high blood pressure. Bisoprolol marketed under the trade name Zebeta, among others is a beta blocker drug ${ }^{[1-2]}$ most commonly used for heart disease ${ }^{[3-4]}$. This includes in particular high blood pressure ${ }^{[5-6]}$, chest pain ${ }^{[7-8]}$ from insufficient blood flow to the heart, and heart failure ${ }^{[9]}$. It is taken by the mouth. Common side effects include headache $^{[10]}$, feeling tired, diarrhea ${ }^{[11]}$ and swelling of the legs. More serious side effects include worsening asthma ${ }^{[12-13]}$, blocking the ability to recognise low blood sugar ${ }^{[14]}$ and worsening 
heart failure. There are concerns that use during pregnancy may be harmful to the child. Bisoprolol is a selective type in the beta blocker family of drugs.

Cilnidipine is a blocker of the calcium channel ${ }^{[15]}$. Cilnidipine is approved for the treatment of hypertention ${ }^{[16-17]}$. It is a calcium antagonist, followed by an L-type and N-type calcium channel blocking mechanism. Cilnidipine, unlike most calcium antagonists, can work on the $\mathrm{N}$-type calcium channel ${ }^{[18-19]}$ in addition to its role on the L-type calcium channel $^{[20]}$.

\section{Materials and Method}

\section{Materials and Reagents}

Ortho phosphoric acid, water, methanol, acetonitrile, Tri ethyl amine were obtained from Merck India Ltd, Worli, Mumbai, India. Bisoprolol, Cilnidipine and its impurities are acquired from Glenmark pharmaceuticals Company, Bombay.

\section{Equipment}

HPLC (Waters alliance e-2695 consisting of quaternary pump) equipped with a photo diode array detector was used in the isolation, detection and quantitative estimation of bisoprolol and Cilnidipine and it was associated with four impurities. Stationary phase of the column used is X-bridge phenyl (150mmx4.6mm, 5 microns). The out put signal has beenmeasured and evaluated using Empower 2.0 software. Ultrasonic bath has been usedin the preparation of sample purchased in Labman, India. Samples and the weighing standards have been carried out on the endeavour analytic balance.

\section{LC-MS/MS terms and coditions}

The molecular weight of newly developed degradation products were detected using HPLC e-2695 machine fitted with 2998 PDA detector and anMS mass detector. AB SCIEX software has been used for data acquisition and processing. A splitter was put in front on the ESI source, allowing only $35 \%$ of the data to be entered. Standard operating source conditions for bisoprolol and Cilnidipine scanning in positive ESI mode were optimised as follows; fragmentor voltage was set at $80 \mathrm{~V}$, capillary voltage at $3000 \mathrm{~V}$, skimmer at $60 \mathrm{~V}$, nitrogen was used as a drying and nebulizing gas (45 psi). Ultra high pure nitrogen gas has been used as a collision gas.

\section{Buffer preparation}

$1 \mathrm{ml}$ of tri ethyl amine is dissolved in $1 \mathrm{lt}$ of HPLC grade water and changepH-2.5 with ortho phosphoric acid. Filter the solution with $0.45 \mu$ filter paper.

\section{Diluent}

Methanol was used as diluent.

\section{Preparation of Regular stock solution}

Weigh exactly $20 \mathrm{mg}$ of bisoprolol and $40 \mathrm{mg}$ of Cilnidipine standards and transfer to a 100 $\mathrm{ml}$ volumetric flask, then add $70 \mathrm{ml}$ of methanol diluent and sonicate for $15 \mathrm{~min}$ to dissolve the content and make up the diluent mark.

\section{Preparation of Stock solution for Impurity}

Weigh accurately $5 \mathrm{mg}$ each of bisoprolol impurity-A, bisoprolol impurity-B and Cilnidipine impurity-1, Cilnidipine impurity-2 standards and trasfer into $100 \mathrm{ml}$ flask, then add $70 \mathrm{ml}$ of methanol diluent and sonicate for $20 \mathrm{~min}$ to dissolve the content and make up the mark with same diluent. Further dilute $2 \mathrm{ml}$ of the above solution to $10 \mathrm{ml}$. 


\section{Preparation of standard solution}

Transfer $5 \mathrm{ml}$ of the standard stock and $5 \mathrm{ml}$ of impurity stock solution to $50 \mathrm{ml}$ volumetric flask and made up to the mark with diluent. Filter with 0.45 micron filter paper.

\section{Conditions of chromatography}

An instrument of the HPLC system (waters alliance e-2695) connected to the LC-MS/MS (Qtrap 5500 triple quadrupole) was used to develop and validate the method. The compound and its associated impurities were separated by using $\mathrm{X}$-bridge phenyl column with dimensions of $150 \mathrm{mmx} 4.6 \mathrm{~mm}, 3.5$ microns. The peaks were separated by using gradient elution mode with a flow $1 \mathrm{ml} / \mathrm{min}$ of mobile phase containing methanol and tri ethyl amine. UV detection was captured at $224 \mathrm{~nm}$, injection volume was fixed at $10 \mu \mathrm{l}$. Table 1 shows the gradient programme.

Table 1. Gradient programme

\begin{tabular}{|c|c|c|}
\hline Time $(\min )$ & Mobile phase-A (Methanol) & Mobile phase-B (buffer) \\
\hline 0 & 70 & 30 \\
\hline 5 & 60 & 40 \\
\hline 10 & 40 & 60 \\
\hline 12 & 70 & 30 \\
\hline 17 & 80 & 20 \\
\hline
\end{tabular}

\section{Method validation}

\section{System suitability}

Machine fitness parameters have been measured to check the efficiency of the model. Parameters including USP plate count, USP tailing and percent RSD were calculated and found to be within the limits.

\section{Specificity}

Specificity is the capacity to test the analyte unmistakably in theabsence of many other materials that might be required to have been present in a sample and the standard. It was checked by examining chromatograms of blank samples and samples spiked with bisoprolol and Cilnidipine and their impurities.

\section{Accuracy}

Accuracy is the proximity to the true value of the test results obtained bythe method. The recovery studies were evaluated at three different levels of concentration. At each level a minimum of three injections were given and the number of the drugsexisting, that proportion of recovery and the associated standard deviation were measured.

\section{Precision}

The consistency of the analytical process is the degree of consensus between the actual testing results. Analysis of the multiple sampling of the homogeneous sample was studied. The reliability of the present procedure was tested in terms of reproducibility, intraday and interday variations. It was checked by analyzing the samples at different time intervals on the same day as well as on different days.

\section{Linearity and range}

Linearity of the test technique has been its ability to obtain results which were inversely proportional to the quantity of the analyte in a sample within a given range. The calibration curve was prepared using peak area versus regular solution concentration and the regression 
equations was determined. The least square formula was used to measure the slope, intercept and coefficient of correlation.

\section{Robustness}

The robustness of an analytical technique is a measure of its ability to remain uninvolved yet deliberate changes in process parameters and to show its reliability during regular use. The robustness analysis was conducted by injecting standard solution into the HPLC system and by altering chromatographic conditions like flow rate $( \pm 0.2 \mathrm{ml} / \mathrm{min})$, organic matter content with in mobile phase $( \pm 10 \%)$. The separation factor, retention time and peak asymmetry were calculated by determining the effect of the modified parameters.

\section{Degrading stress}

The peaks in the chromatogram should agree. ICH guidance Q1(A) R2 was performed in conjunction with stress degradation experiments. The peaks of degradation should be well distanced and at least 1.0 resolution between peaks. For the largest peaks to go over, a separation must occur. A degradation of around 20 percent has been attained via several various stress conditions like acid, alkali, peroxide, reduction, thermal and photo in what is known as a forced degradation experiment.

\section{Results and Discussion}

\section{Optimization of method}

Development pathways have been under taken to achieve good resolution between bisoprolol, Cilnidipine and its impurities. Several proportions of buffer and water in the mobile phase with isocratic and gradient modes have been tested to optimize chromatographic conditions. However, at each trial the mobile phase composition was modified in order to improve resolution and also to achieve acceptable retention times. In the end 0.1 percent tri ethyl amine and methanol in gradient elution was selected as the result of a higher response to the production of pharmaceutical ingredients and their impurities and the use of methanol as diluent. Various stationary phases such as $\mathrm{C}_{8}, \mathrm{C}_{18}$, Cyano and phenyl columns have been used during the optimization of the method. On the basis of these trials it was found that the peak shapes of the active ingredients and all impurities were relatively good on the X-bridge phenyl $150 \mathrm{mmx} 4.6 \mathrm{~mm}, 3.5 \mu$ column connected to a PDA detector. The mobile phase flow rate was $1.0 \mathrm{ml} / \mathrm{min}$. UV detection was performed at $224 \mathrm{~nm}$ to achieve sufficient sensitivity between the analyte and all impurities. Under these conditions, the best response between impurities and analyte was achieved when impurity spiked solution was injected. The resoluion, theoretical plate count, tailing factor and percent RSD of bisoprolol and Cilnidipine and its impurities are within an acceptable range indicate that the method is accurate. The method developed was validated in accordance with the ICH guidelines, with all results within the limit.

\section{Method validation}

\section{System suitability}

System suitability parameters such as USP plate count of bisoprolol was 3652 and Cilnidipine was 5984, USP tailing of bisoprolol was 1.01 and Cilnidipine was 1.06 , percent RSD values of bisoprolol was 0.24 and Cilnidipine was 0.49 . The measured values were found to be within the limit. Figure 1 represents the chromatogram of standard. 


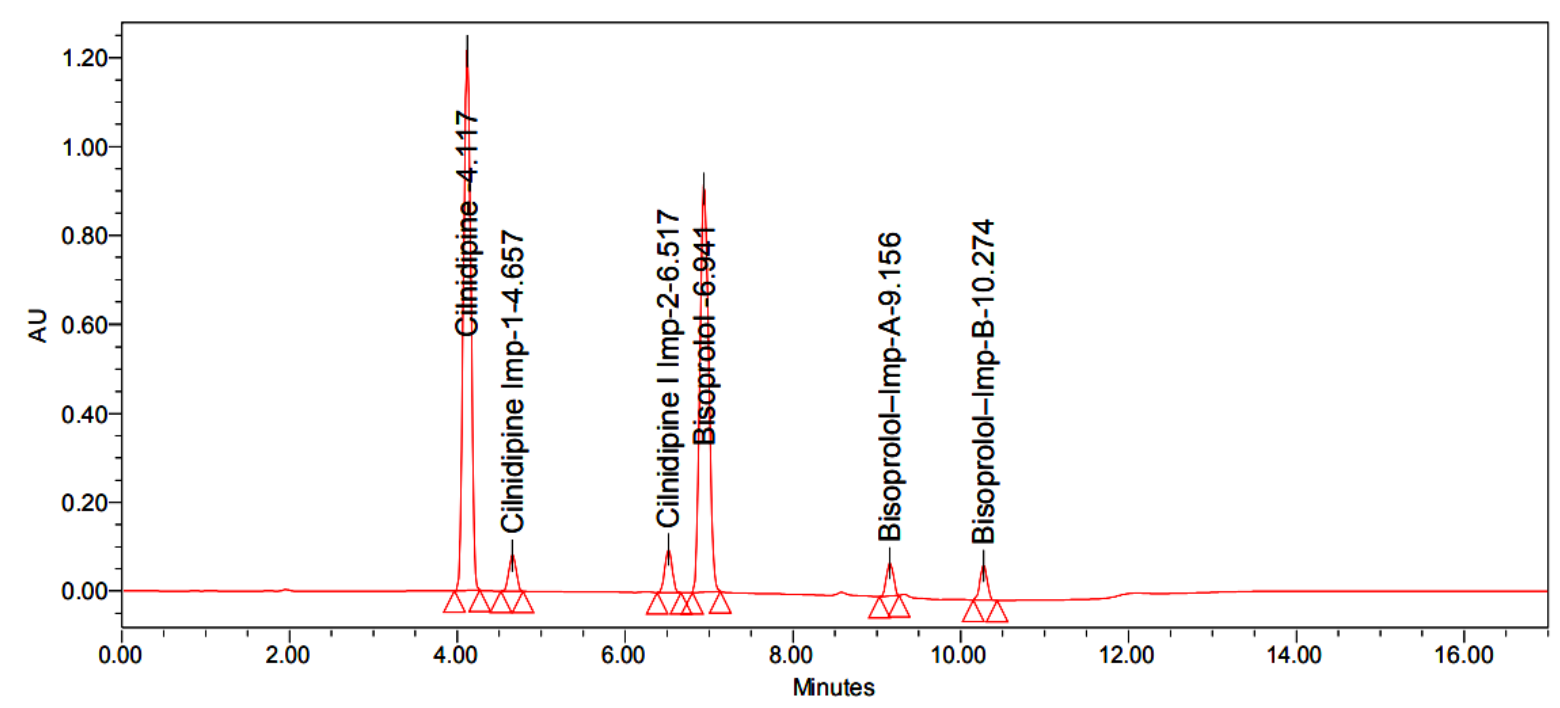

Figure 1. Chromatogram for Standard

\section{Specificity}

Sample and standard solutions were analysed individually to examine the interference according to the placebo test method. The following figures show that the active ingredients were well separated from the blanks and their excipients, and there was no placebo interference with the main peak, so the method is specific. Figure 2 shows the chromatogram of blank.

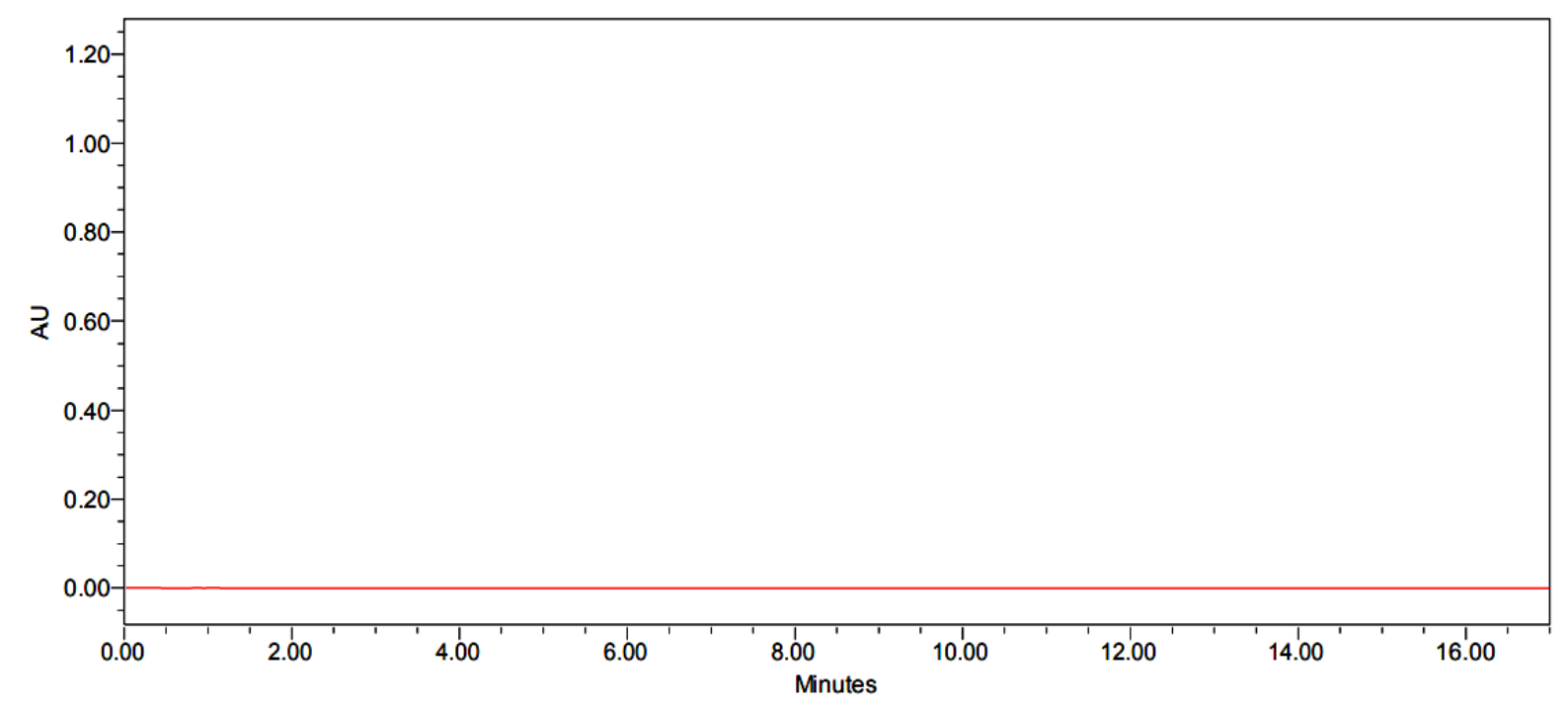

Figure2. Chromatogram for Blank

\section{Linearity}

The linearity plots of bisoprolol, Cilnidipine and its related impurities were drawn by taking area of the peak on $\mathrm{Y}$-axis and their respective concentrations on $\mathrm{X}$-axis. Test solutions were prepared for the related impurity stock solution substance method at different concentration levels. The linearity range was found to be $2 \mu \mathrm{g} / \mathrm{ml}$ to $30 \mu \mathrm{g} / \mathrm{ml}$ for bisoprolol, $0.1 \mu \mathrm{g} / \mathrm{ml}$ to $1.5 \mu \mathrm{g} / \mathrm{ml}$ of bisoprolol imp-1, $0.1-1.5 \mu \mathrm{g} / \mathrm{ml}$ of bisoprolol imp-2, $4 \mu \mathrm{g} / \mathrm{ml}$ to $60 \mu \mathrm{g} / \mathrm{ml}$ of Cilnidipine, $0.1 \mu \mathrm{g} / \mathrm{ml}$ to $1.5 \mu \mathrm{g} / \mathrm{ml}$ of Cilnidipine imp- 1 and $0.1 \mu \mathrm{g} / \mathrm{ml}$ to $1.5 \mu \mathrm{g} / \mathrm{ml}$ of Cilnidipine imp-2. Under optimal chromatographic conditions, linear relations between the peak areas and the corresponding concentrations were found. Correlation coefficients for all components were under the limit. Figure 3 shows the linearity plots of bisoprolol, Cilnidipine 
and its related impurities. Table 2 gives the linearity data of bisoprolol, Cilnidipine and their related impurities.

Tabel 2. Results of Linearity

\begin{tabular}{|c|c|c|c|c|c|c|c|c|c|}
\hline \multirow{2}{*}{ Linearity } & \multicolumn{6}{|c|}{ Area } & \multicolumn{3}{|c|}{ Conc. $(\mu \mathrm{g} / \mathrm{ml})$} \\
\hline & Bis & Cil & Bis I-1 & Bis I-2 & Cil I-1 & Cil I-2 & Bis & Ciln & All Imps \\
\hline Lin-1 & 723654 & 821510 & 55412 & 65177 & 43510 & 39812 & 2 & 4 & 0.1 \\
\hline Lin-2 & 1859642 & 2179127 & 126534 & 172712 & 99912 & 97837 & 5 & 10 & 0.25 \\
\hline Lin-3 & 3532987 & 4225672 & 252301 & 338507 & 222567 & 182790 & 10 & 20 & 0.5 \\
\hline Lin-4 & 7023654 & 8296959 & 523695 & 679429 & 400695 & 386985 & 20 & 40 & 1 \\
\hline Lin-5 & 8763251 & 10325244 & 631254 & 807194 & 502524 & 471081 & 25 & 50 & 1.25 \\
\hline Lin-6 & 10425961 & 12338079 & 754210 & 1021180 & 615807 & 572775 & 30 & 60 & 1.5 \\
\hline
\end{tabular}

Bis-Bisoprolol

Bis I-1-Bisoprolol Impurity-1

Bis I-2-Bisoprolol Impurity-2
Cil I-1-Cilnidipine Imp-1

Cil I-2-Cilnidipine Imp-2

All Imps-Bisoprolol Imp-1, Bisoprolol Imp-2, Cilnidipine Imp-1, Cilnidipine Imp-2
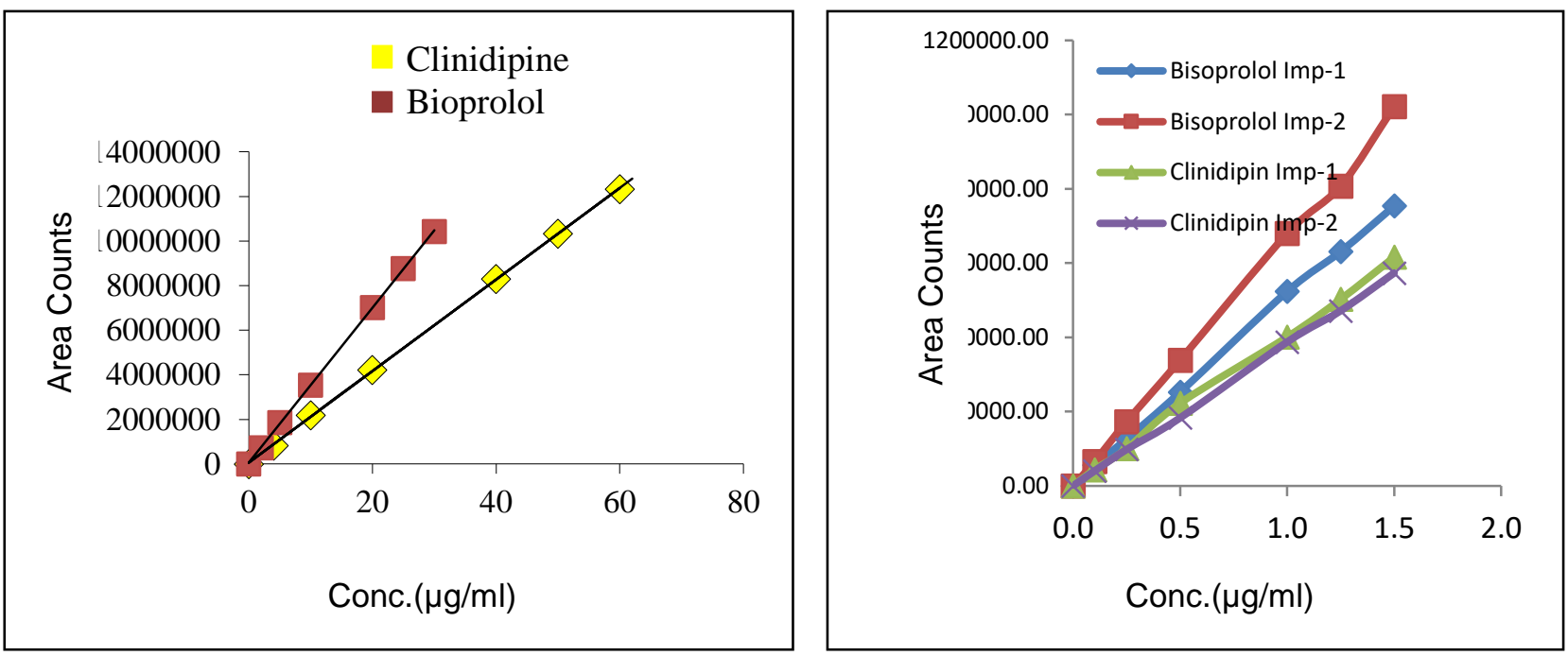

Figure 3. Linearity Chromatograms For Bisoprolol, Clinidipine and their Impurities

\section{Accuracy}

Accuracy was conducted by triplicate by analyzing active pharmaceutical ingredients (bisoprolol and Cilnidipine) sample solution spiked with known amounts of all related impurities at three concentration levels of 50,100 and 150 percent of each at a specified limit. The percentage recovery for all impurities was calculated and ranges from 99.8- 100.9 percent. Table 3 represents the accuracy data of bisoprolol and Cilnidipine.

Table 3. Results of accuracy

\begin{tabular}{|c|c|c|c|}
\hline \multirow{2}{*}{ S. No } & \multirow{2}{*}{ \% Level } & \multicolumn{2}{|c|}{ \% Recovery } \\
\cline { 3 - 4 } & & Bisoprolol & Cilnidipine \\
\hline 1 & 50 & 100.4 & 99.9 \\
\hline 2 & 100 & 100.8 & 99.6 \\
\hline 3 & 150 & 99.5 & 100.5 \\
\hline
\end{tabular}

\section{Precision}

The precision of the analytical technique is the degree of proximity of a series of measurements derived from multiple samples of a homogeneous mixture. Precision of the related substance method was achieved by injecting six individual determinations of bisoprolol and Cilnidipine spiked with that of their related impurities and the percent RSD 
was calculated for each impurity and these results showed that the method is precise under the specified experimental conditions. Table 4 represents the precision data of bisoprolol and Cilnidipine.

Table 4. Precision results

\begin{tabular}{|c|c|c|c|c|}
\hline \multirow{2}{*}{ Sample Number } & \multicolumn{4}{|c|}{$\%$ Purity } \\
\cline { 2 - 5 } & \multicolumn{2}{|c|}{ Intra day Precision } & Inter day Precision \\
\cline { 2 - 5 } & Bisoprolol & Cilnidipine & 94.35 & 94.23 \\
\hline 1 & 94.62 & 94.13 & 94.33 & 94.25 \\
\hline 2 & 94.54 & 94.16 & 94.37 & 94.26 \\
\hline 3 & 94.55 & 94.18 & 94.32 & 94.21 \\
\hline 4 & 94.61 & 94.15 & 94.36 & 94.27 \\
\hline 5 & 94.58 & 94.11 & 94.31 & 94.28 \\
\hline
\end{tabular}

\section{$L O D$ and $L O Q$}

LOD and LOQ of the compounds were carried out by progressively injecting lower concentrations of the standard solutions. The LOD concentrations of bisoprolol, its impurities 1,2 were $0.061,0.003,0.003 \mu \mathrm{g} / \mathrm{ml}$ and their $\mathrm{s} / \mathrm{n}$ values were $6,4,3$ and Cilnidipine, its impurities were $0.12,0.003,0.003 \mu \mathrm{g} / \mathrm{ml}$ and their s/n values were $7,3,3$. LOQ values for bisoprolol, its impurities were $0.2,0.01,0.01 \mu \mathrm{g} / \mathrm{ml}$ and their s/n values were $25,23,23$ and the LOQ values for Cilnidipine, its impurities were $0.4,0.01,0.01$ and their $\mathrm{s} / \mathrm{n}$ values were $27,23,23$ respectively.

\section{Robustness}

In order to measure the robustness of the developed method, the conditions of the experiment have been deliberately changed, such as flow rate, organic percentage of the mobile phase. In all these varied conditions, the resolution of impurities between active pharmaceutical ingredientswere not significantly affected and there was no significant influence on retention time, plate count and tailing factor. There fore the method was robust. The results of robustness was shown in table 5 .

Table 5. Results of Robustness

\begin{tabular}{|c|c|c|}
\hline \multirow{2}{*}{ Parameter name } & \multicolumn{2}{|c|}{ \% RSD for purity } \\
\cline { 2 - 3 } & Bisoprolol & Cilnidipine \\
\hline Flow (0.8 ml/min & 0.64 & 0.86 \\
\hline Flow (1.2 ml/min) & 0.38 & 0.41 \\
\hline Org Phase (-10\%) & 0.57 & 0.78 \\
\hline Org Phase (-10\%) & 0.29 & 0.34 \\
\hline
\end{tabular}

\section{Degradation studies}

Forced degradation samples under different conditions were analysed at an initial concentration of $20 \mu \mathrm{g} / \mathrm{ml}$ of bisoprolol and $40 \mu \mathrm{g} / \mathrm{ml}$ of Cilnidipine by spiking with known impurities using a PDA detector to ensure homogeneity of bisoprolol and Cilnidipine peaks. Degradation studies were conducted as follows: hyrolysis in acidic medium $\left(1 \mathrm{~N} \mathrm{HCl}\right.$ at $60^{\circ} \mathrm{C}$ for $15 \mathrm{~min}$.), hydrolysis in basic medium $\left(1 \mathrm{~N} \mathrm{NaOH}\right.$ at $60^{\circ} \mathrm{C}$ for $15 \mathrm{~min}$.), peroxide degradation $\left(30 \% \mathrm{H}_{2} \mathrm{O}_{2}\right.$ at $30 \mathrm{~min}$ ), reduction degradation (30 percent $\mathrm{NaHCO}_{3}$ at $60^{\circ} \mathrm{C}$ for 15 min.). Results were provided in table 6.Using LC-MS/MS, the degradants were characterized.Figure 4 represents the degradation schems of bisoprolol and Cilnidipine and the mass spectras of DPs were shown in figure 5-11.

Table 6. Results of Forced degradation

\begin{tabular}{l|l|l|} 
Degradation condition & $\%$ purity of Bisoprolol & $\%$ purity of Cilnidipine \\
\hline
\end{tabular}




\begin{tabular}{|c|c|c|}
\hline Acid degradation & 78.62 & 75.19 \\
\hline Alkali degradation & 75.36 & 78.32 \\
\hline Peroxide degradation & 72.17 & 73.65 \\
\hline Reduction degradation & 98.17 & 97.56 \\
\hline Thermal degradation & 96.34 & 95.19 \\
\hline Photolytic degradation & 82.45 & 81.58 \\
\hline Hydrolysis degradation & 77.36 & 75.36 \\
\hline
\end{tabular}

Chromatograms For Bisoprolol, Clinidipine and their Impurities

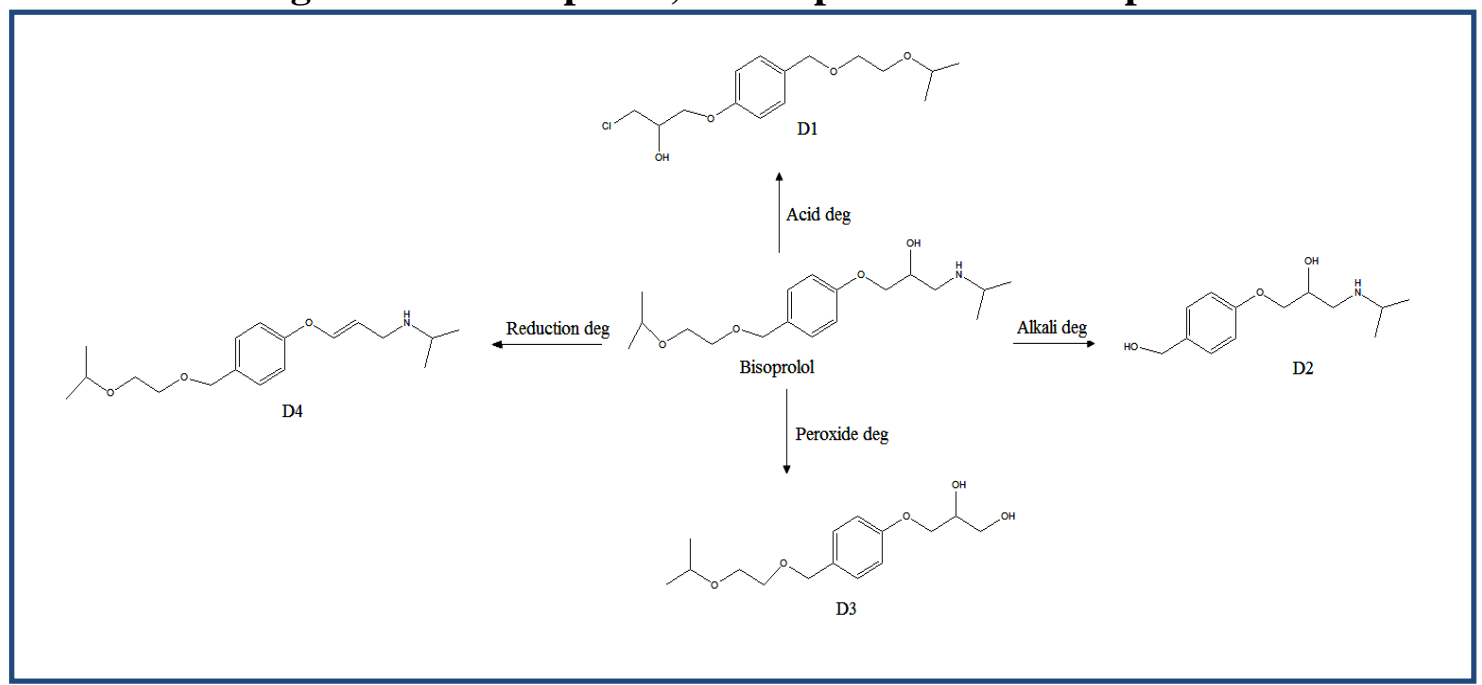

4(A)

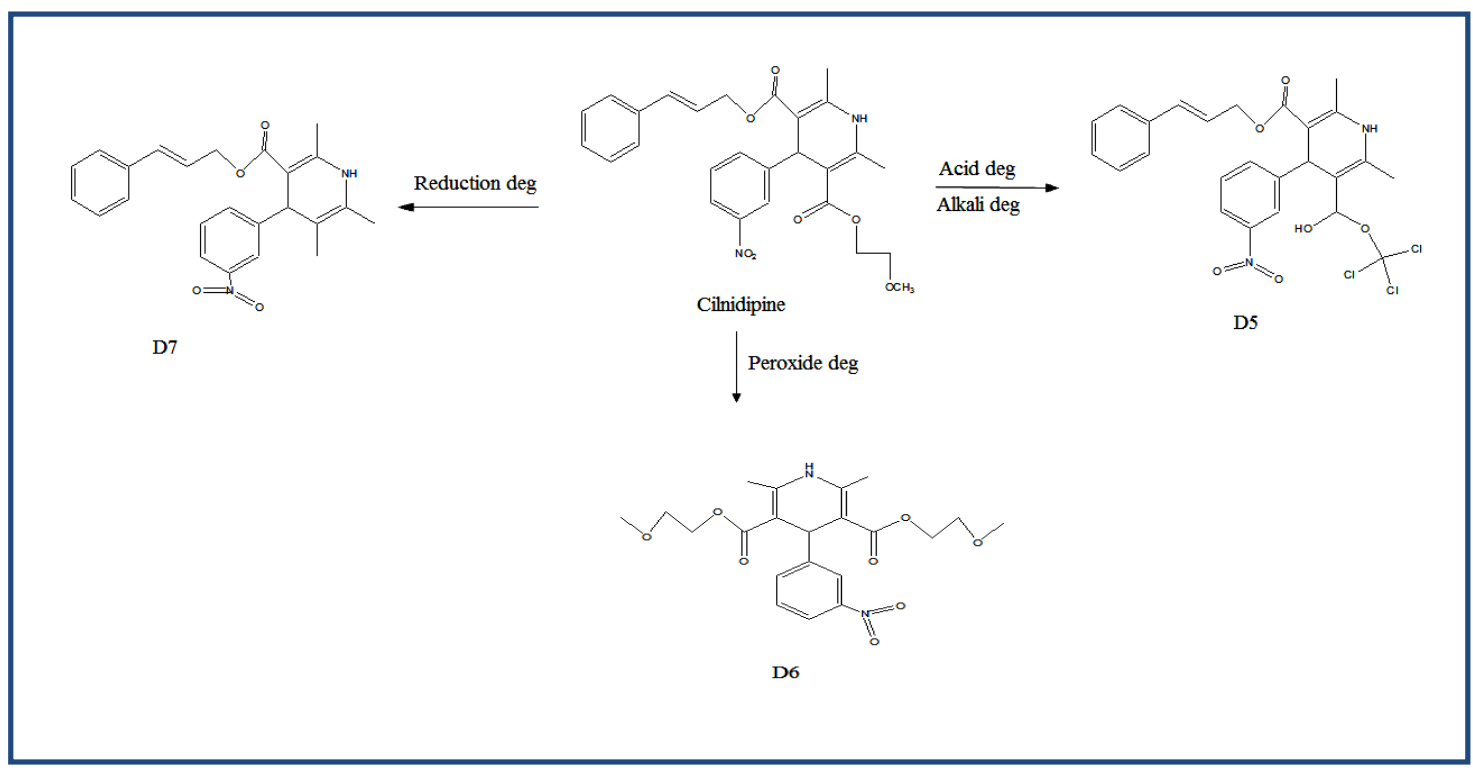

4(B)

Figure 4. Forced Degradation Schemes

\section{Characterization of DPs by LC-MS/MS:}

\section{Scheme-1:}

Bisoprolol degradation product-1 was fragmented under acid degeneration conditions as shown in Scheme 1. Extensive spectra can be seen for the loss of $\mathrm{C}_{3} \mathrm{H}_{8} \mathrm{O}$ at $\mathrm{m} / \mathrm{z}-244.09$, for 
the loss of $\mathrm{C}_{3} \mathrm{H}_{8} \mathrm{O}$ at $\mathrm{m} / \mathrm{z}-186.05$, and for the loss of $\mathrm{C}_{3} \mathrm{H}_{7} \mathrm{ClO}_{2}$ at $\mathrm{m} / \mathrm{z}-78.05$ (both from $\mathrm{m} / \mathrm{z}$ 244.09). The suggested approach has been validated by MS/MS studies and precise mass measurements.

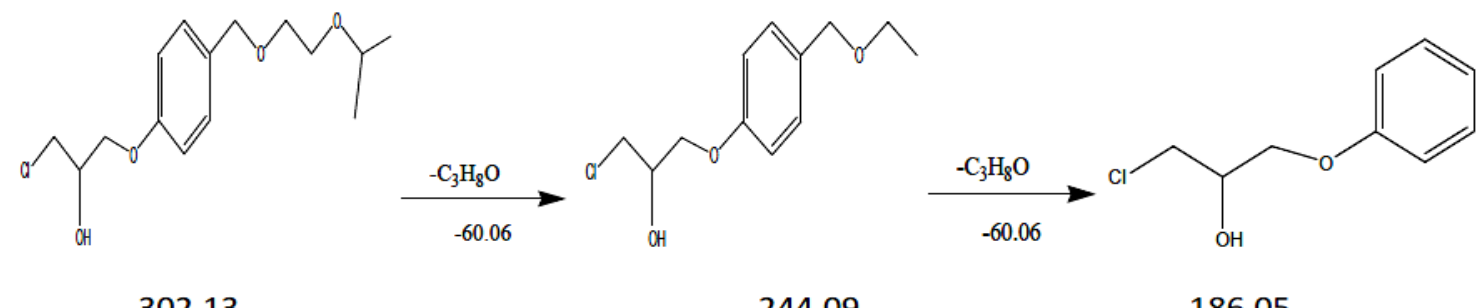

302.13

244.09

186.05
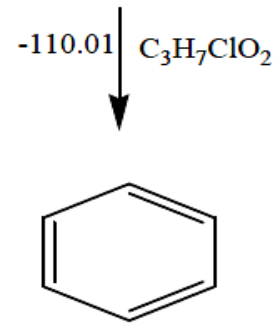

78.05

Degradation Product-1 fragmentation pathway

\section{Scheme-2:}

Bisoprolol degradation product -2 fragmentation pathway is shown in Scheme 2 under Alkali degeneration conditions. At m/z-182.09 (loss of $\mathrm{C}_{3} \mathrm{H}_{9} \mathrm{~N}$ ) and m/z-108.05 (loss of $\mathrm{C}_{3} \mathrm{H}_{8} \mathrm{O}_{2}$ from $\mathrm{m} / \mathrm{z} 182.09$ ), the spectrum shows copious product ions. The suggested approach has been validated by MS/MS studies and precise mass measurements.

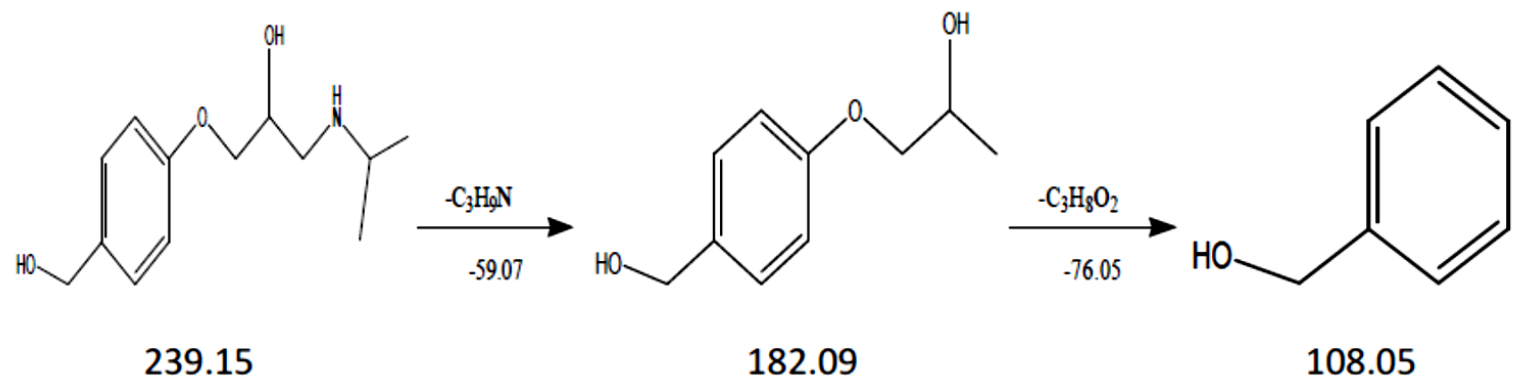

Degradation product-2 fragmentation pathway

\section{Scheme-3:}

Under the conditions of Peroxide degeneration, the fragmentation mechanism of Bisoprolol degradation product -3 was observed. $\mathrm{C}_{3} \mathrm{H}_{8} \mathrm{O}, \mathrm{C}_{3} \mathrm{H}_{8} \mathrm{O}$, and $\mathrm{C}_{3} \mathrm{H}_{8} \mathrm{O}_{3}$ are all lost at $\mathrm{m} / \mathrm{z}-226.12$, $\mathrm{m} / \mathrm{z}-168.08$, and $\mathrm{m} / \mathrm{z}-78.05$, respectively, according to the spectrum. With the use of MS/MS studies and precise mass measurements, the suggested methodology has been proven. 


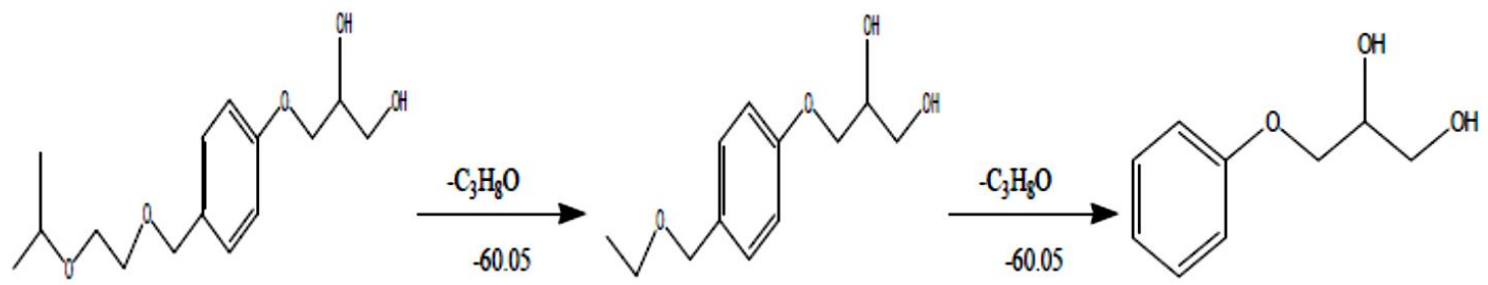

284.16

226.12

168.08
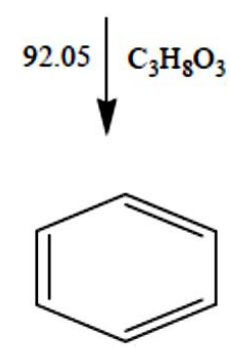

78.05

\section{Degradation product-3 fragmentation pathway}

\section{Scheme-4:}

Depicts the breakdown of Bisoprolol degradation product -4 under reduction degeneration circumstances. A large number of product ions can be seen in the spectrum at $\mathrm{m} / \mathrm{z}-250.16$ (loss of $\mathrm{C}_{3} \mathrm{H}_{9} \mathrm{~N}$ ), m/z-194.13 (loss of $\mathrm{C}_{3} \mathrm{H}_{6} \mathrm{O}$ ), and $\mathrm{m} / \mathrm{z}-78.05$ (loss of $\mathrm{C}_{6} \mathrm{H}_{14} \mathrm{O}_{2}$ ). The suggested approach has been validated by MS/MS studies and precise mass measurements.

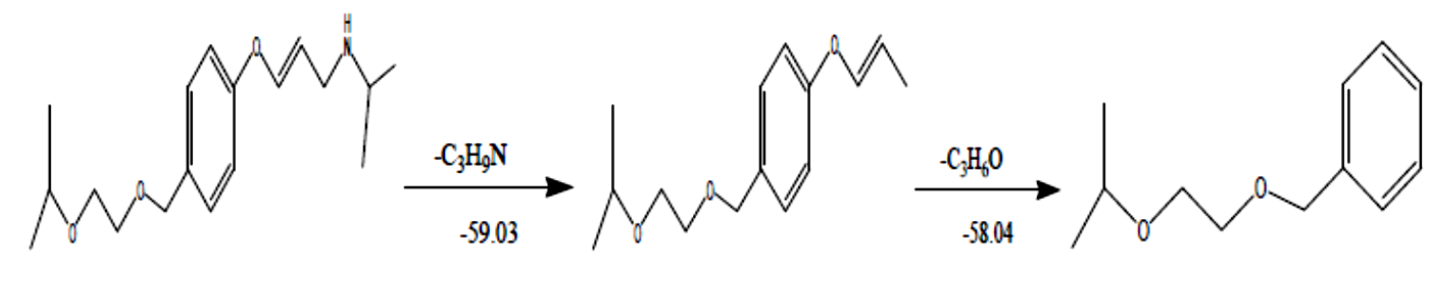

307.21

250.16

194.13

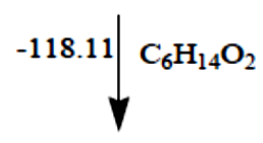<smiles>c1ccccc1</smiles>

78.05

\section{Scheme-5:}

\section{Degradation product-4 fragmentation pathway}

When Cilnidipine was degraded in acidic and alkaline settings, the fragmentation mechanism of -5 was seen. $\mathrm{C}_{6} \mathrm{H}_{4} \mathrm{~N}_{2}$ is lost at $\mathrm{m} / \mathrm{z}-431.05, \mathrm{~m} / \mathrm{z}-390.16$ (loss of $\mathrm{C}_{2} \mathrm{H}_{2} \mathrm{O}_{2} \mathrm{Cl}_{3}$ ), m/z-269.14 (loss of $\mathrm{C}_{6} \mathrm{H}_{4} \mathrm{NO}_{2}$ from m/z 390.16), m/z-193.11 (loss of $\mathrm{C}_{6} \mathrm{H}_{5}$ from m/z 269.14), m/z-109.09 (loss of $\mathrm{C}_{4} \mathrm{H}_{4} \mathrm{O}_{2}$ from $\mathrm{m} / \mathrm{z}$ 193.11). The suggested approach has been validated by MS/MS studies and precise mass measurements. 
<smiles>CC1=C(C(=O)OC/C=C/c2ccccc2)C(c2cccc([N+](=O)[O-])c2)C(C(O)OC(Cl)(Cl)Cl)=C(C)N1</smiles>

552.06<smiles>CCOCCCCCCCCCCCOC(=O)C1=C(C)NC(C)=CC1c1cccc([N+](=O)[O-])c1</smiles>

390.16<smiles>C=CCOC(=O)C1=C(C)NC(C)=CC1</smiles>

193.11

269.14

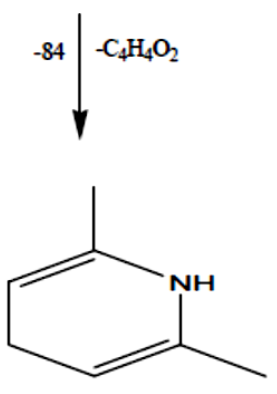

109.09

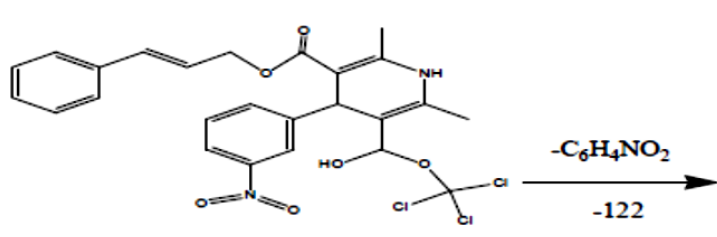

552.06

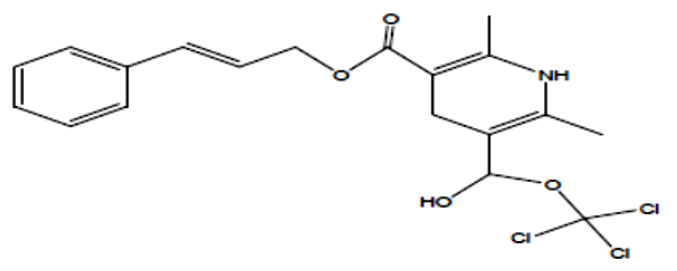

431.05

\section{Scheme-6:}

Degradation product-5 fragmentation pathway

Cilnidipine degradation product -6 was fragmented under Peroxide degeneration conditions, as seen in Scheme 6. It's clear that the m/z-332.14 (loss of C4H8O3), m/z-230.11 (loss of C4H8O3), $\mathrm{m} / \mathrm{z}-109.09$ (loss of C6H4NO2), and m/z-313.15 (loss of C6H4NO2 from $\mathrm{m} / \mathrm{z}$ 434.17) are the most common product ions in the spectrum. With the use of MS/MS studies and precise mass measurements, the suggested methodology has been proven. 


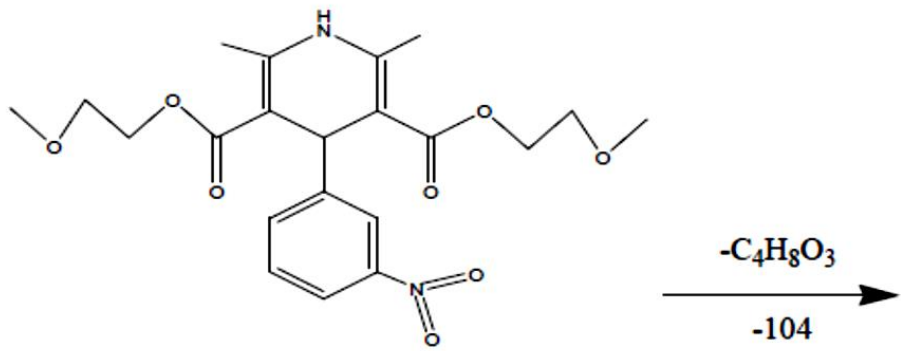

434.17

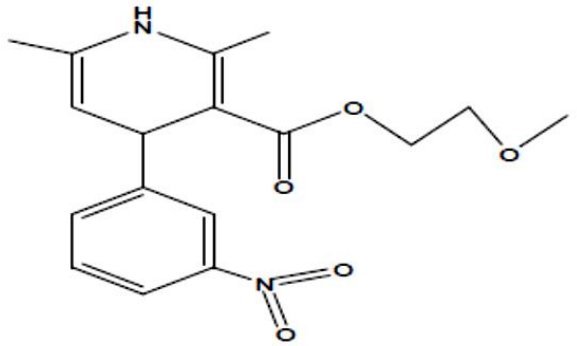

332.14

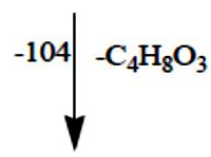

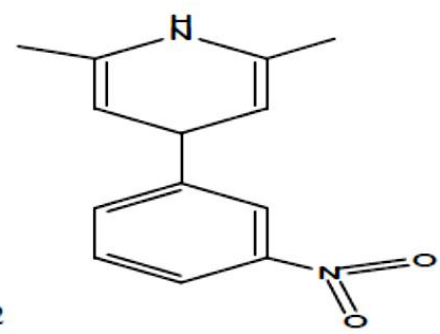

230.11<smiles>COCCOC(=O)C1=C(C)NC(C)=C(C(=O)OCCOC)C1c1cccc([N+](=O)[O-])c1</smiles>

434.17

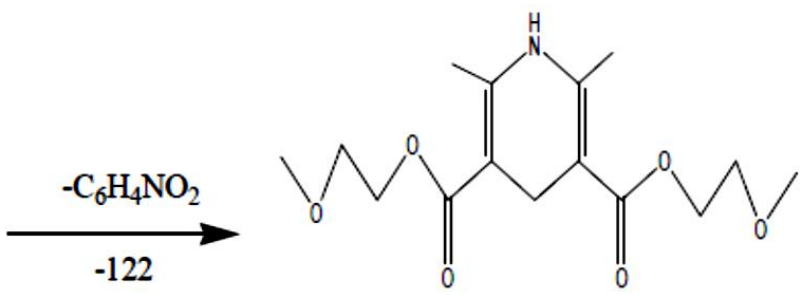

313.15

\section{Degradation product-6 fragmentation pathway}

\section{Scheme-7:}

Under reduced degeneration conditions, the fragmentation process of Cilnidipine degradation product -7 is shown in Scheme 7. m/z-328.14 (loss of $\mathrm{C}_{6} \mathrm{H}_{5}$ ), m/z-207.13 (loss of $\mathrm{C}_{6} \mathrm{H}_{4} \mathrm{NO}_{2}$ ), $\mathrm{m} / \mathrm{z}-123.11$ (loss of $\mathrm{C}_{4} \mathrm{H}_{4} \mathrm{O}_{2}$ ), m/z-244.12 (loss of $\mathrm{C}_{10} \mathrm{H}_{9} \mathrm{O}_{2}$ ), are the most common product ions. With the use of MS/MS studies and precise mass measurements, the suggested methodology has been proven. 


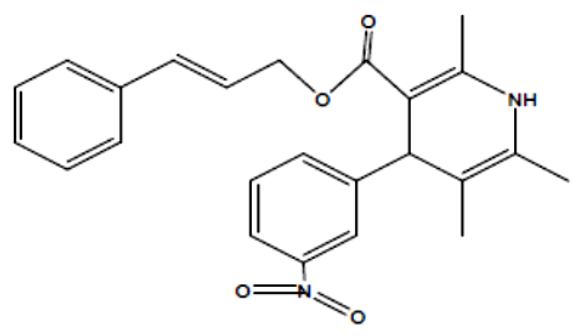

404.17

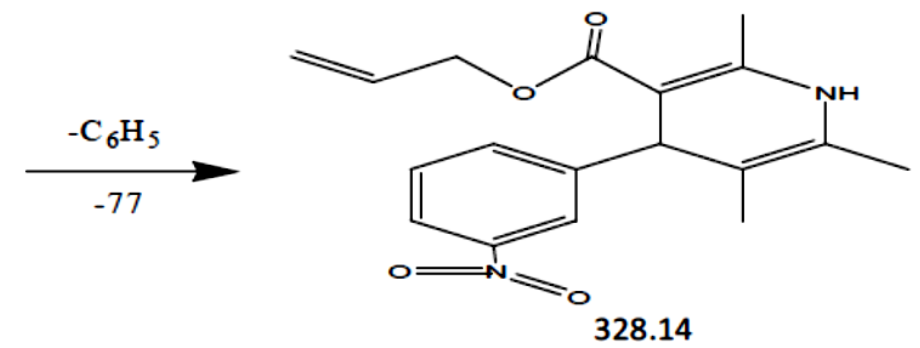

$$
-122\rfloor-\mathrm{C}_{6} \mathrm{H}_{4} \mathrm{NO}_{2}
$$

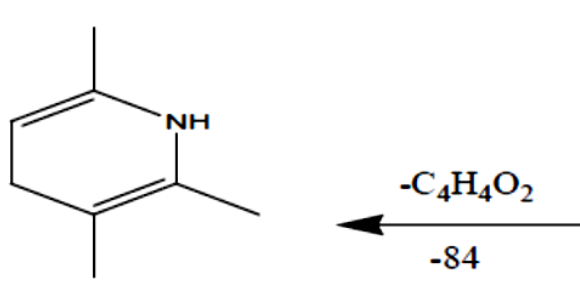

123.11

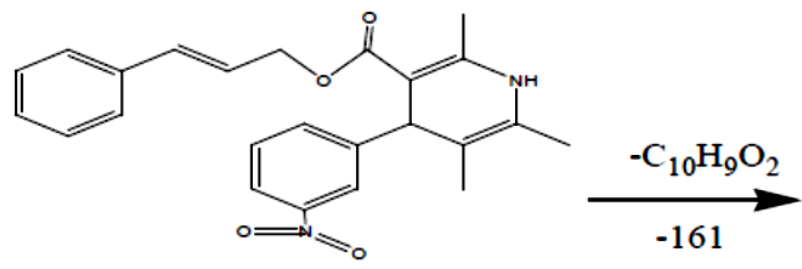

404.17

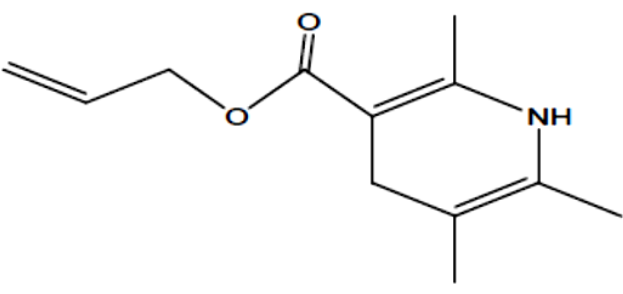

207.13

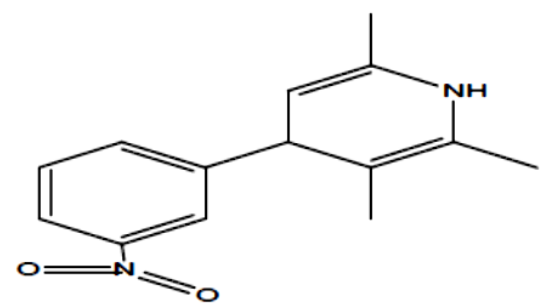

244.12

Degradation product-7 fragmentation pathway 


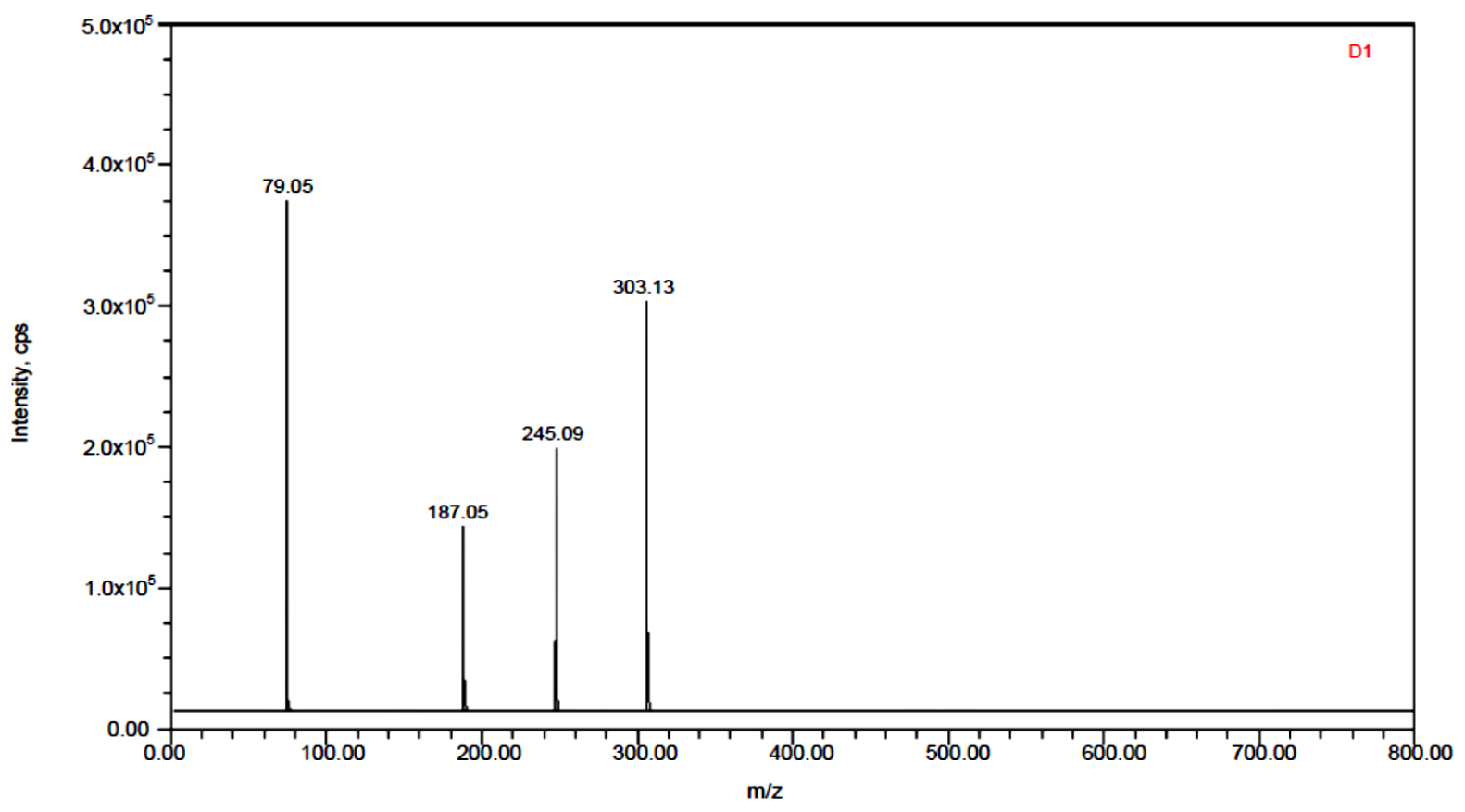

Figure 5. Mass spectra of DP-1

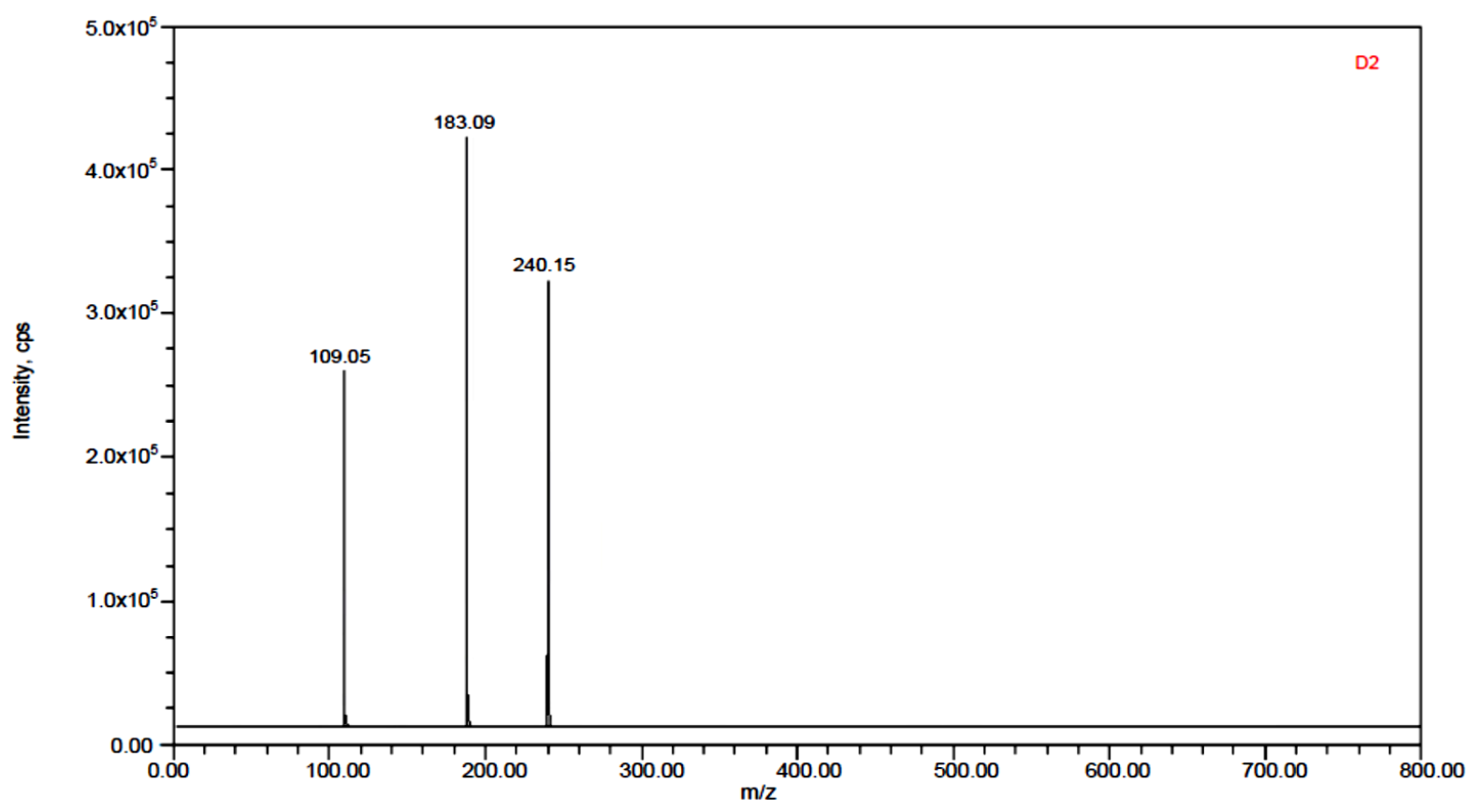

Figure 6. Mass spectra of DP-2 


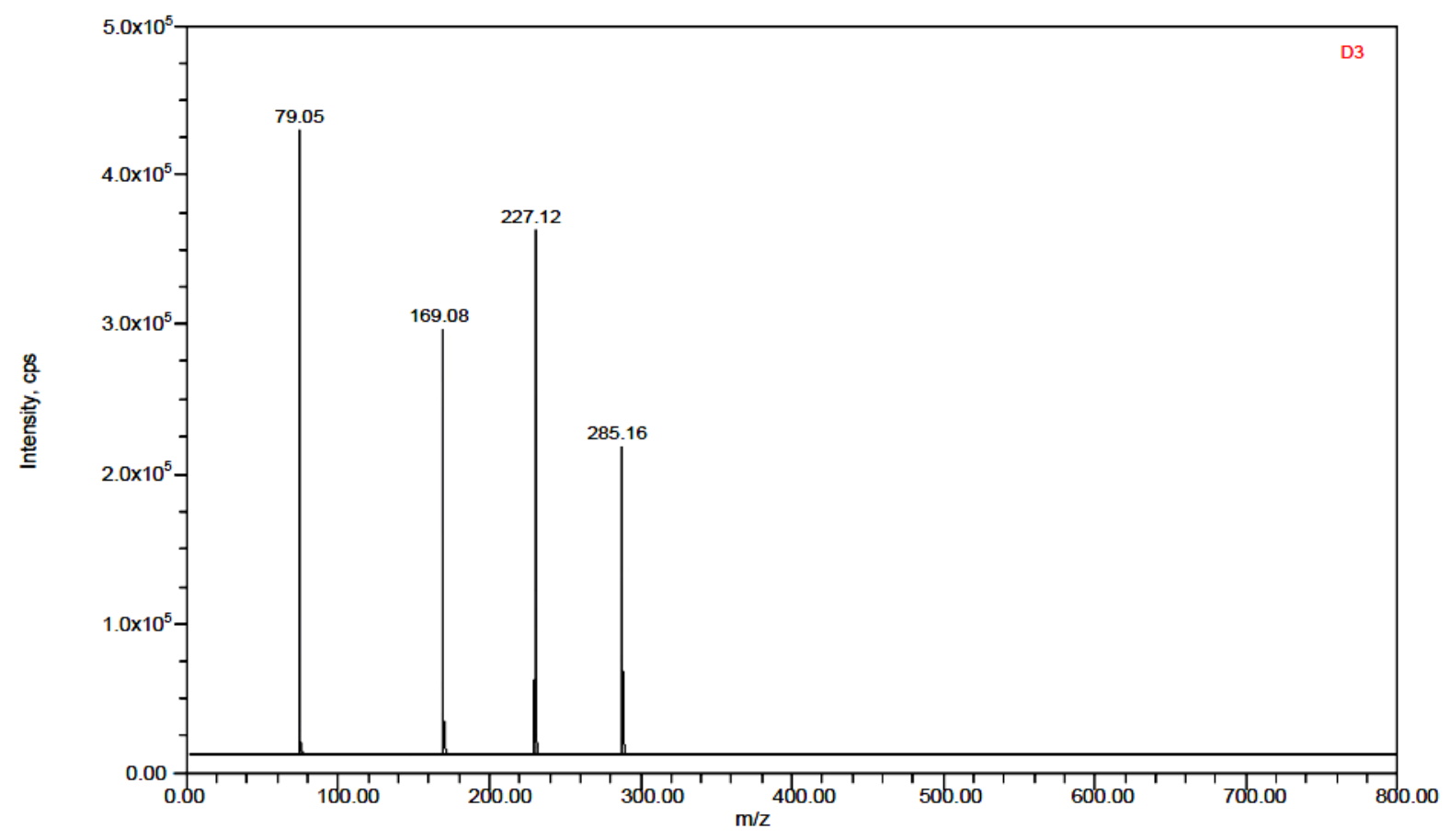

Figure 7. Mass spectra of DP-3

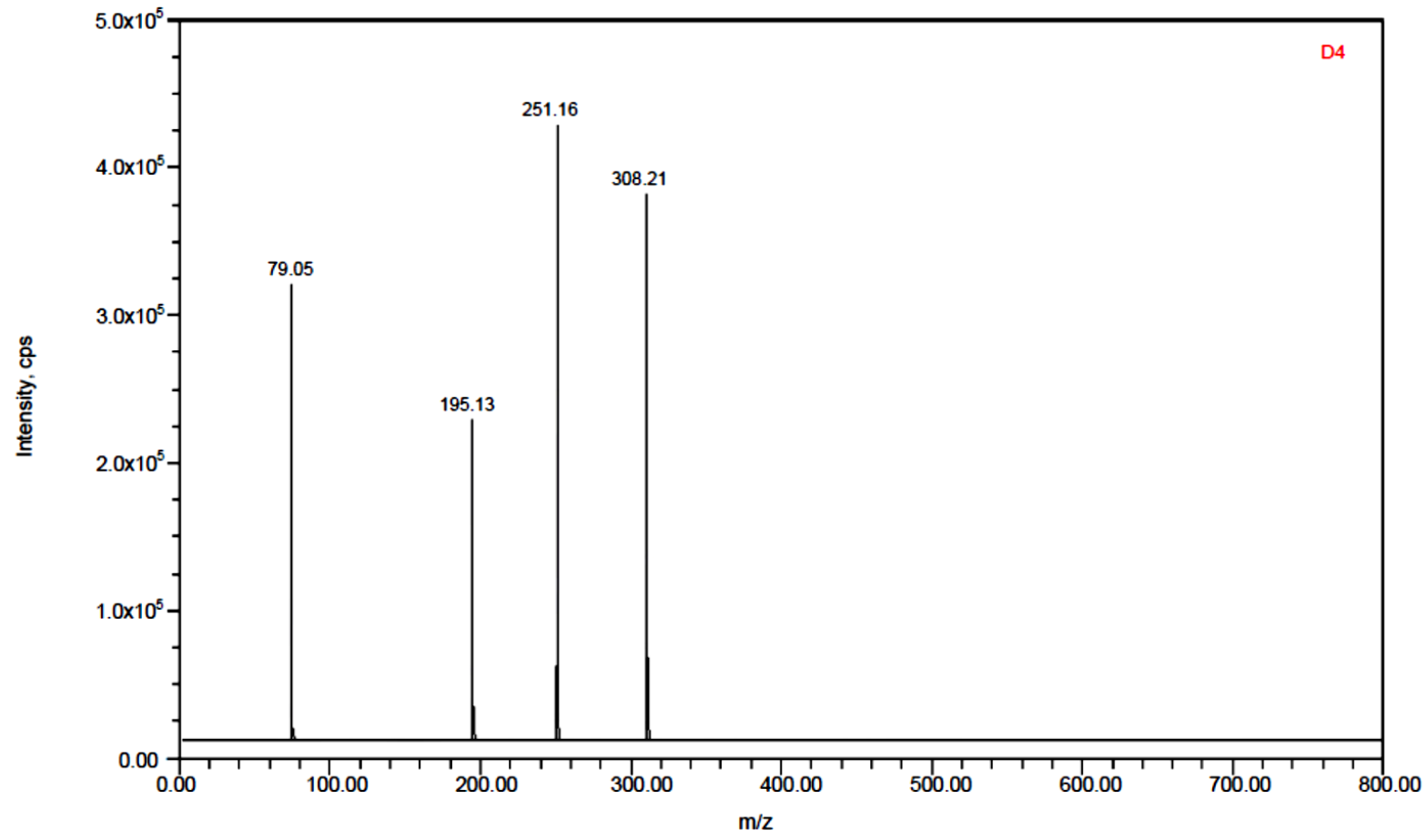

Figure 8. Mass spectra of DP-4 


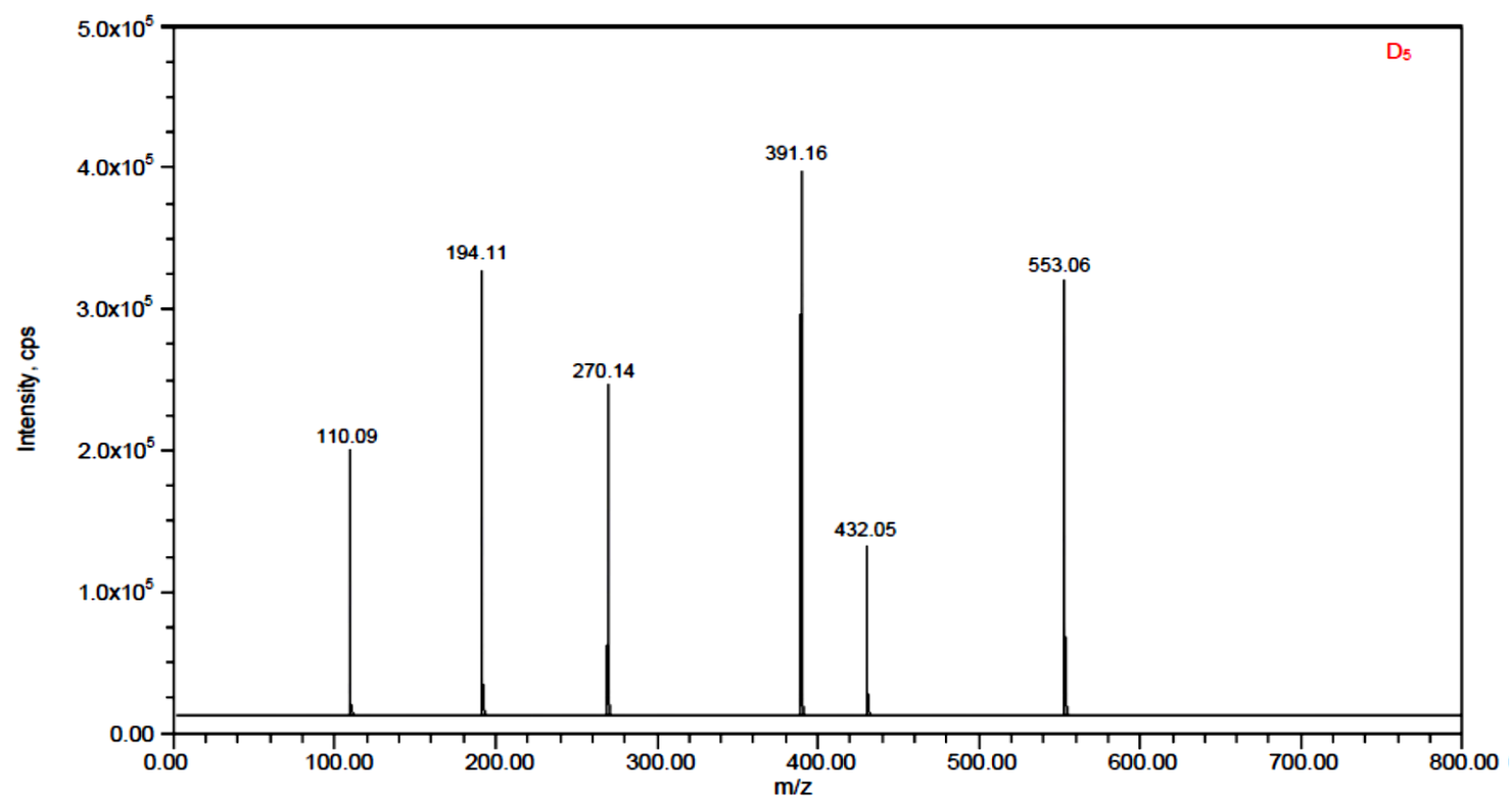

Figure 9. Mass spectra of DP-5

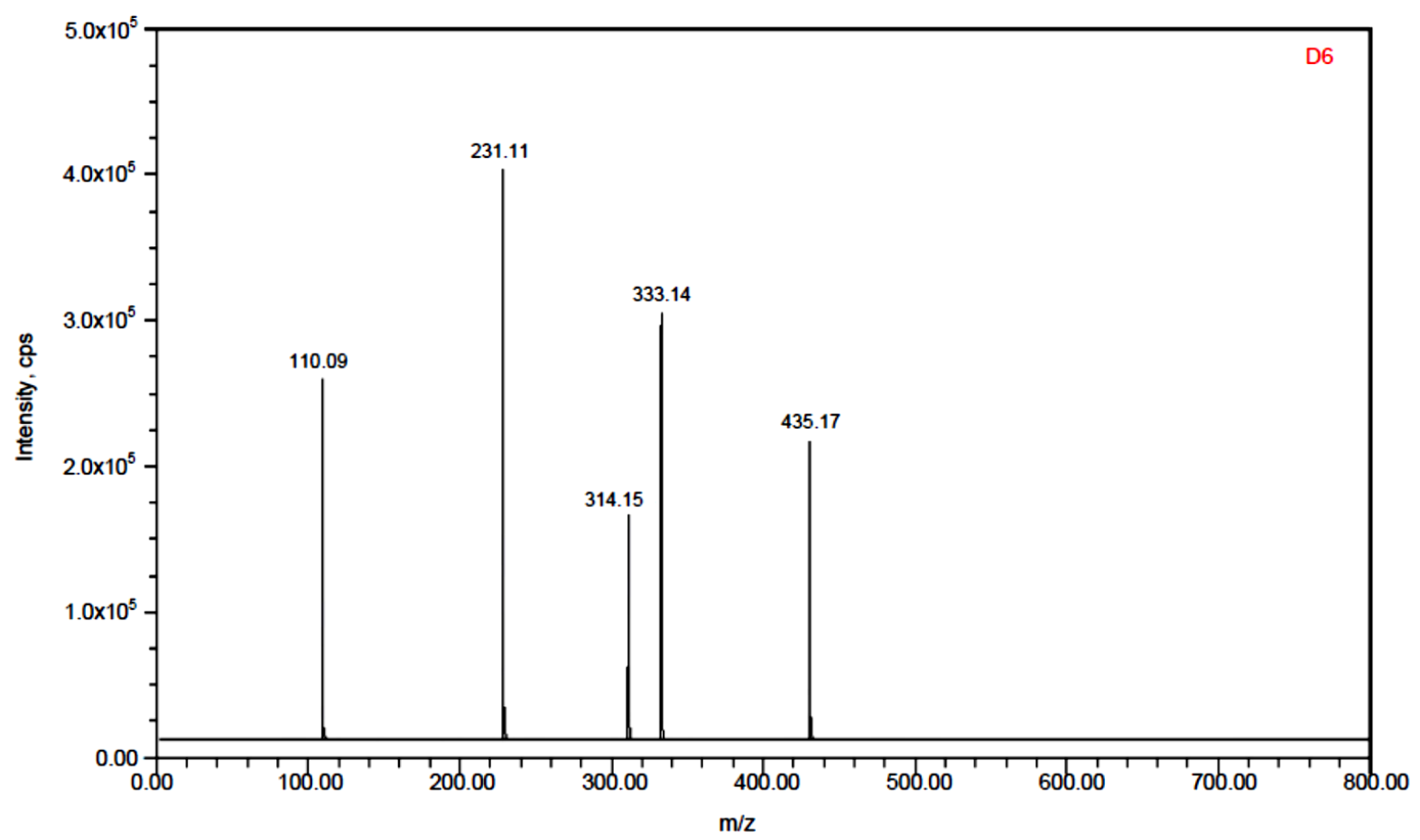

Figure 10. Mass spectra of DP-6 


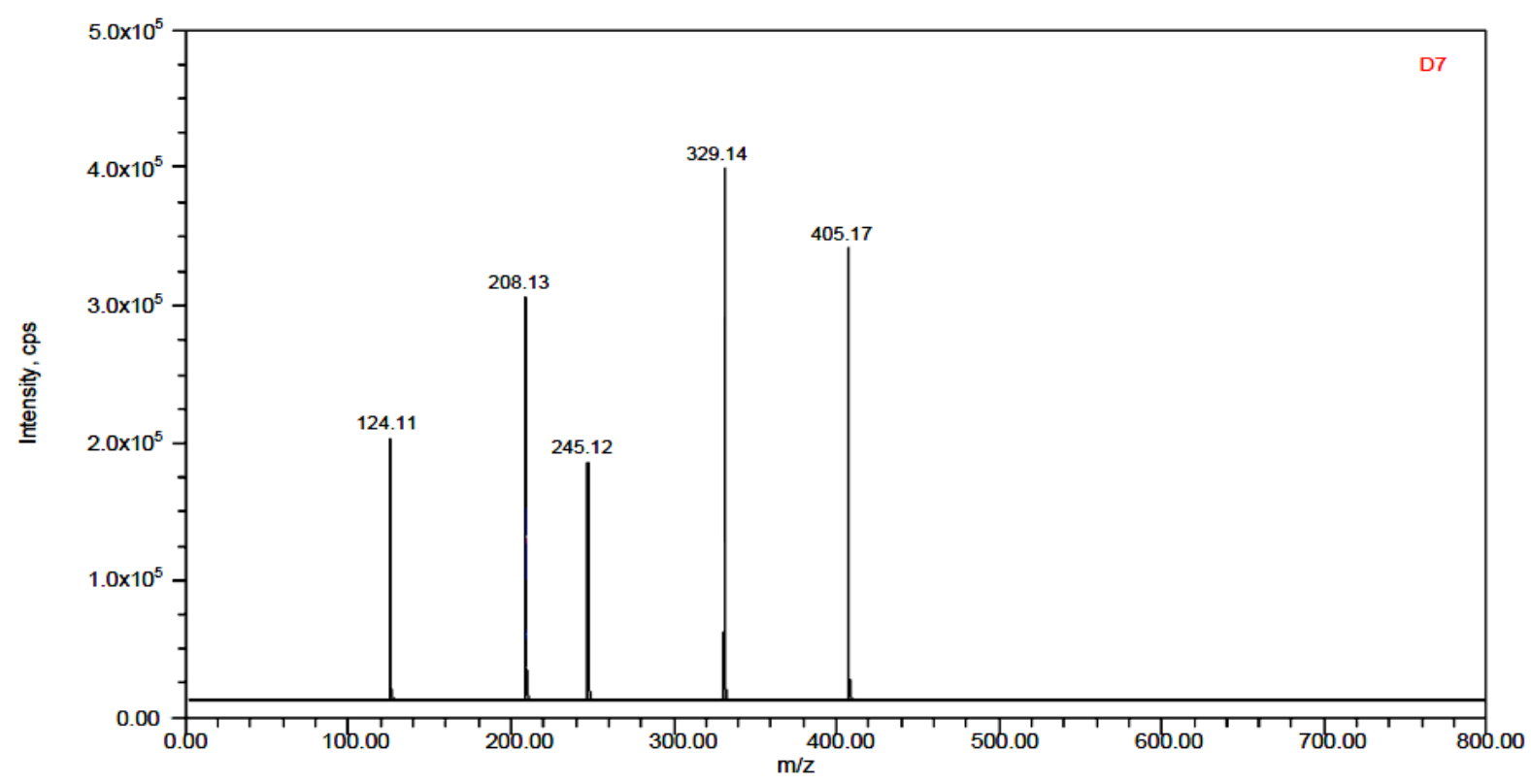

\section{Conclusion}

Figure 11. Mass spectra of DP-7

This paper presents a simple, selective, validated and well defined stabilitiy indicating gradient RP-HPLC method for the quantitative determination of bisoprolol and Cilnidipine, as well as their chromatographic impurities. All degradation products formed during stress conditions and associated impurities of active pharmaceutical ingredients are well separated and the peaks have been well resolved and separated with an appropriate retention time, indicating that the proposed method has been shown to be fast, simple, feasible and affordable for robustness. This developed method can therefore be used for routine analysis of the production samples and to check the quality of the drug samples during stability studies.

\section{Acknowledgement} sugestions.

The authors are thankful to Subba Rao M for giving his valuable guidelines and

\section{Conflicts of interest}

Authors declare that there was no conflicts of interest.

\section{Funding source}

None

\section{References}

[1] Zipursky, JS., Macdonald, EM., Luo, J., Gomes, T., Mamdani, MM., Paterson, JN., Jurrlink, DN. 2017. Lipophilic $\beta$-blockers and suicide in the elderly. Journal of clinical psychopharmacology,37, 381-384.

[2] Morales, Daniel R., Jackson, Cathy., Lipworth, Brian J., Donnan, Peter T., Guthrie, Bruce. 2014. Adverse respiratory effect of acute $\beta$-blocker exposure in asthma. Chest. Elsevier BV, 145, 779-786.

[3] Kwok, CS., Pradhan, A., Khan, MA., Anderson, SG., Keavney, BD., Myint, PK., et al. 2014. Bariatric surgery and its impact on cardiovascular disease and mortality, a systematic review and meta analysis. International journal of cardiology,173, 20-8. 
[4] Liu, Wei., Cao, Yubin., Dong, Li., Zhu, Ye., Wu, Yafei., Lv, Zongkai., Iheozor-Ejiofor, Zipporah., Li, Chunjie. 2019. Peridontal therapy for primary or secondary prevention of cardiovascular disease in people with periodontitis. The cochrane database of systematic reviews, 12, CD009197.

[5] Poulter, NR., Prabhakaran, D., Caulfield, M. 2009. Hypertension. Lancet,386, 801-12.

[6] Palatini, P., Julius, S. 2009. The role of cardiac autonomic function in hypertension and cardiovascular disease. Current hypertension reports, 11,199-205.

[7] Schey, R., Villarrealm, A., Fass, R. 2007. Noncardiac chest pain. Current treatment. Gastroenterology \& Hepatology,3, 255-62.

[8] Backus, BE., Six, AJ., Kelder, JC., Bosschaert, MA., Mast, EG., Mosterd, A., et al. 2013. A prospective validation of the HEART score for chest pain patients at the emergency department. International journal of cardiology, 168, 2153-8.

[9] Mahtani, KR., Heneghan, C., Onakpoya, I., Tierney, S., Aronson, JK., Roberts, N., et al. 2018. Reduced salt in take for Heart failure. A systematic review. JAMA internal medicine, 178, 1693-1700.

[10] Charles, A. 2013. Vasodilation out of the picture as a cause of migraine head-ache. Lancet Neurol,12, 419-420.

[11] Das, S., Jayaratne, R., Barrett, KE. 2018. The role of iron transporters in the pathophysiology of infectious diarrhea. Cellular and molecular gastroenterology and hrpatology,6, 33-45.

[12] Van de Loo, KF., van Gelder, MM., Roukema, J., Roeleveld, N., Merkus, PJ., Verhaak, CM. 2016. Prenatal maternal psychological stress and childhood asthma and wheezing, a meta analysis. A European respiratory journal,47, 133-46.

[13] Martinez, FD. 2007. Genes, Environments, development and asthma: a reappraisal. The European respiratory journal, 29, 179-84.

[14] Yanai, H., Adachi, H., Katsuyama, H., Moriyama, S., Hamasaki, H., Sako, A. 2015. Causative antidiabetic drugs and the underlying clinical factors for hypoglycemia in patients with diabetes. World journal of diabetes, 6, 30-6.

[15] Sica, Domenic A. 2003. Calcium channel blocker related peripheral edema. Can it be resolved. The journal of clinical hypertension Wiley,5, 291-295.

[16] Hernandorena, I., Duron, E., Vidal, JS., Hanon, O. 2017. Treatment options and considerations for hypertensive patients to prevent dementia. Expert opinion on pharmacotherapy (review), 18, 989-1000.

[17] Go, AS., Bauman, MA., Coleman King, SM., Fonarow, GC., Lawrence, W., Williams KA., Sanchez, E. 2014. An affective approach to high blood pressure control; a science advisory from the American Heart Association, the American college of cardiology, and the centers for disease control and prevention. Hypertension,63, 878-85.

[18] Molderings, GJ., Likungu, J., Gothert, M. 2000. N-type calcium channels control sympathetic neurotransmission in human heart atrium. Circulation,101, 403-7.

[19] Adams David, J., Berecki, Geza. 2013. Mechanisms of conotoxin inhibition of N-type calcium channels. Biochimica et Biophysica Acta (BBA) Biomembranes, 1828, 1619-1628.

[20] Shaw, RM., Colecraft, HM. 2013. L-type calcium channel targetting and local signalling in cardiac myocytes. Cardiovascular research,98, 177-86. 